\title{
Predictors of the Use of ICTS in Higher Education: Relevance and Readiness of Universities for Their Implementation
}

\author{
https://doi.org/10.3991/ijet.v16i14.20047 \\ Elena Tokareva ${ }^{\bowtie}$, Olga Malysheva, Yulia Smirnova, \\ Larisa Orchakova \\ Moscow City University, Moscow, Russian Federation \\ elenatokareva396arambler.ru
}

\begin{abstract}
Nowadays higher education that does not implement information and communication technologies (ICTs) is inconceivable; this place new demands on the level of qualification of teachers and the development of professional competencies in students. Therefore, the study of the readiness of universities for the introduction of ICTs is a relevant issue. The purpose of the research is to determine the predictors of the readiness of higher educational institutions for the introduction of ICTs. For this purpose, 218 students and 196 teachers of Moscow City University (Russia) were interviewed. Our research involves studying the issue of using information and communication technologies in teaching humanitarian specialties, and in the future it is planned to expand it to other faculties of Moscow State University, and also to compare it with other universities in Russia and other countries. The respondents were asked to fill in a specially designed questionnaire that included 40 key questions aimed at assessing the use of ICTs and their impact on student performance. The data analysis involved the following two steps: determining the level of ICT use in the educational process and comparing the indicators of the two groups of respondents - students and teachers. Lack of awareness of students on the introduction of new methods of learning in the educational institution was revealed in the course of the study. Although students and teachers note the steady development of the use of ICT in the educational process, they are not inclined to assess this area as the leading strategic goal of the institution. The primary task of ICT use in higher education is to train teachers and improve their skills. The use of ICT improves the quality of education and competitiveness of higher educational institutions, contributes to the development of professional competencies, but does not have a significant impact on the academic performance of students. Predictors of the use of ICTs in higher education are blended learning focused on the use of online technologies and independent work of students, virtual laboratories, as well as the development of open education and the MOOC system. The development of standardized quality control criteria will ensure the equality of diplomas in online and offline education.
\end{abstract}


Keywords - Distance learning; higher educational institution; ICTs (information and communication technologies); predictors; quality of education; students; teachers

\section{Introduction}

Global changes raise the problem of preserving the status of education as an inalienable human right and public good [1]. This necessitates innovations in the educational process, among which the use of ICTs is a priority today [2], which is also related to the introduction of open education and its theoretical justification [1]. Higher educational institutions have started to increasingly often implement online learning programs; it is crucial for the competitiveness of universities, which are interested in improving and ensuring the quality of education they provide (QOE) [3]. Despite the active use of the Internet by most teachers and especially students, the use of information and communication technologies in higher education is hampered by the number of economic, technological, and psychological problems, difficulties and limitations. The unexpected global quarantine in connection with the COVID-19 pandemic has forced educational institutions in many countries to suddenly switch to distance learning. Despite the temporary nature of the solution, it has accelerated the technologization of the educational process of many educational institutions, revealed the problems of the uneven distribution of hardware and staffing of universities in different countries and regions, raised a number of serious issues related to the educational process, the change in the role of teachers, students' self-management and independent work skills, as well as showed the need for the readiness of universities to operate in the context of the changing paradigm of higher education. Currently, the competitiveness of higher education is determined by the quality of education received by students, one of the components of which is the introduction of modern information and communication technologies that offer new opportunities for obtaining the information needed, conducting research, learning foreign languages, and interacting with foreign colleagues. At the same time, there is a popular stereotype that the quality of classroom learning that provides direct contact of students with the teacher and classmates is better. While the need for informatization and technologization of the educational process is obvious, not all universities are equally ready for innovative changes, and the assessment of the forecast in this area requires appropriate research, which determines the relevance of the study. Scientific literature describes data on the use of ICTs in educational institutions in various European, Asian, African and American countries. However, in our country this problem has not be properly elaborated. Despite the fact that in a number of countries both distance learning and open education have been actively developing for many years, the awareness of the urgent need to introduce ICTs in higher education as a new common phenomenon in the post-Soviet countries arose only in connection with the forced quarantine and revealed that a number of educational institutions do not have up-to-date hardware and appropriate staffing that meet modern requirements. Therefore, the object of our study is the process of using ICTs in higher education; the subject of the study is the readiness of higher educational institutions to implement ICTs. The purpose of the 
study is to determine the predictors of readiness of higher educational institutions to implement ICTs.

The research objectives are as follows:

1. To study the data of the scientific literature on the introduction of ICTs in the educational process.

2. To study the readiness of students and teachers of Moscow City University to use ICTs.

3. To identify the predictors of the use of ICTs in higher education and develop practical recommendations for higher educational institutions.

It is hypothesized that the use of ICTs in higher educational institutions improves the quality of education and student performance, as well as contributes to the development of their professional competencies.

\section{$2 \quad$ Literature Review}

The problem of quality assurance in higher education using information technology. ICT systems generally facilitate the educational process [4]. At the same time, quality assurance plays a key role in the success of electronic learning; therefore, the introduction of quality standards is crucial for the competitiveness of universities [3]. Despite the lack of a holistic quality structure of open education [4], the ISO/IEC 40180 framework for quality assurance, quality management, and quality improvement in IT-enhanced education is a flexible and adaptable framework for revolutionary organizational changes that meet the needs of a number of stakeholders in educational organizations at the macro, meso and micro levels; at the same time, most standards relate to the design of online courses and online programs [3]. However, a number of modern structures and models for assessing the quality of education are based on theoretical conclusions - they have not been validated, are of non-specific nature and do not take into account technological evolution or different types of digital media and resources that can be integrated into learning [3]. The concepts and applications of quality assurance systems in higher education derive from the changing values associated with the dynamic relationship of education with social, economic, cultural, and technological development, primarily due to the growth of various types of distance and online learning in recent decades [5,6]. New approaches to and ways of defining and measuring the quality of higher education are being developed so that students and the public can choose high-quality programs that meet their academic and professional goals [7]. There are guidelines on the definitions of and approaches to the quality of education, in particular in the field of online learning in higher education; these are designed to guide future research and policy support in this area $[6,8]$.

Features of the implementation of online learning at universities in different countries. The study of the features of the introduction of online learning in higher education in the Middle East and North Africa [9] has shown that the UAE leads the way in the transition to online and distance learning followed by Jordan and Egypt. The UAE 
pioneered online learning at the regional level due to its huge financial resources. There are few barriers to the recognition of online qualifications in the United Arab Emirates, and Hamdan Bin Mohammed Smart University has been at the forefront of setting national e-learning standards. Currently, it is the leader in connecting with online and blended learning universities around the world, as well as in initiating research and development programs in the field of online education [9]. However, personal interaction in the educational process is preferred.

In Jordan [9], blended learning is prevalent; universities introducing components of online education in their qualifications get more credits in the quality assessment process, but fully online programs are not yet accredited, and professional qualifications awarded exclusively on the basis of online training currently do not allow getting a job in the government or the civil service. The problem is poor Internet connection outside the capital, which negatively affects the development and distribution of online programs [9].

In Egypt, the introduction of blended e-learning in higher education is coordinated by the National E-Learning Center and involves the conversion of traditional modules currently used in face-to-face learning into the modules to be used on the Moodle system that is compatible with the EKB. Online qualifications are commonly recognized for vocational training and private tuition, as well as for obtaining a degree [9].

Problems and risks of using information and communication technologies in higher education. However, the following issues and risks of using information and communication technologies in higher education are being discussed: the potential risk of excessive generalization of modules in different educational institutions, which will lead to the loss of identity by individual universities and diversity; practical aspects of removing textbooks from the educational process and the role of libraries in the future, especially in the face of resistance to online texts and teaching in higher education; the prevalence and expansion of online learning and information resources without further development of broadband connectivity and the coverage of areas where there is a lack of coverage or insufficient coverage [9].

A common problem is the lack of skills required for online learning and selfstudying, and the popularity of traditional higher education indicates that the belief in the value of classroom learning still dominates [9]. Issues such as provision of resources to and support for minorities and groups with special needs, such as people with physical disabilities and sensory impairments, have not been resolved $[9,10]$. In addition, there is a growing need for people who can adapt professional skills in the rapidly changing environment created by the deployment of intellectual education [9].

It should be noted that while in Europe and North America distance learning is being actively introduced - and it often prevails, especially in the last year, due to the quarantine - the educational culture in the Middle East and North Africa is still focused mainly on face-to-face training. However, the growth of blended learning observed there indicates that online learning is becoming more acceptable. This step combined with increased technological availability is likely to further shift the balance towards online learning. Teacher readiness is still a major obstacle to broader and further implementation. Pedagogical models are often transmissible, and organizational culture does not encourage innovation, which does not allow the introduction 
of new forms of teaching and learning. The problem of teacher readiness is associated with the need to invest in pedagogy [9].

In general, the available approaches are reduced to two alternative models. One of them suggests that online learning should be considered as a unique approach and be regulated by law. According to the second one, online learning should be treated in the same way as any other form of learning given that the issues of good pedagogy, institutional support, teacher quality, etc. are common to all types of education [9]. Neither of them is necessarily better, but countries need to clearly understand which model they prefer and why. This may also be related to the scale and level of decentralization in education with more fragmented systems, which may be more difficult to organize and regulate [9].

Information and communication technologies can be used in various forms in higher education [11]. For example, they have proven effective in learning foreign languages [12]. In addition, to facilitate the teaching process, there are web applications, in particular, diagrammER, which was developed for information technology and system undergraduates and allows modeling data based on entity-relationship (E-R) diagrams [13].

Open education as a promising area of online learning. Open education, that is online education without admission requirements, is becoming increasingly popular, which expands access to secondary and higher education and removes barriers that may hinder both opportunities and recognition of participation in the learning process. One of the aspects of open education is the development and implementation of open educational resources. Massive open online course is a course aimed at mass interactive participation involving the application of e-learning technologies and open access via the Internet; this is one of the forms of distance education [14]. In addition to traditional course materials such as video, texts, and homework, massive open online courses provide the opportunity to use interactive forums that help users create and maintain communities of students, teachers, and assistants [15]. The role of the teacher is being transformed into the role of the assistant. The philosophy of open education is based on the belief that freedom of choice and guidance of students will improve the quality of education [3,7]. Open education involves the predominant application of Internet technologies with websites being used to provide lecture notes and assessments; means of online communication, online platforms and social networks, such as Skype, YouTube, and Facebook are used to demonstrate videos, conduct discussions, and organize webinars. The course content can also be stored on CDs or other media. Thus, open education provides a wide range of learning opportunities and can be considered as a promising direction for the use of information and communication technologies in the educational process. However, there are a number of serious issues that hamper the development of open education, among which the issue of quality assurance is of paramount importance, including the issues of copyright and unequal access to the Internet and technology in different countries and regions. Therefore, researchers are actively developing approaches to the assessment of student performance in the open education system. The analysis of the data on student performance and the methods of curriculum implementation helps universities to identify differences in the volume of teaching, make the assessment more objective, 
and balance the ratio of disciplines, which will ultimately have a positive effect on student performance [16]. When designing or modifying a curriculum in order to take advantage of digital technologies, there are some key issues that should be considered to ensure the improvement of student performance. Thus, it is important to define the strategic goals of the university related to learning, teaching and assessment; highlight the points to be improved that were identified during the curriculum review; outline expected learning outcomes; review the context of training and the available technologies to improve it; identify the areas of achievement, difficulties, and support needed. This will contribute to quality education and assessment [17]. Experts claim that the quality depends not on the percentage of online content but on the effectiveness of training [17].

To assist educational institutions in expanding online learning, a checklist of key issues that may arise in this process has been made and curriculum development options and the needs of students and teachers have been described [18]. The choice of curriculum design is very important and affects the support that both students and teachers may need. It should be noted that the transformation of current approaches to teaching and assessment to be implemented in online learning can be an extremely challenging task for management, educators and support staff and affect operational processes within the organization.

Actual tasks, strategies and tools for online learning. The transition to fully interactive or blended learning models allows the use of cloud computing networks and services [18]. An important task of online learning is to ensure that online students receive equal services and student experience compared to their peers on campus. First of all, the use of information and communication technologies in the educational process requires the implementation of innovation change management to overcome possible obstacles and difficulties [19].

The Institute of Educational Technology offers students who are being involved in distance and online learning for the first time, as well as teachers who have already taught distance courses and strive to try something new [14] special reference sheets, each of which describes one approach to distance learning, recommendations for its practical application given the fact that students may have limited access to technology and the Internet. The following approaches are distinguished:

- Flipped distance learning is a strategy that makes all learning resources available to students; for example, this can be a slide show, in which each slide contains a link to a resource that students will need. Google Slides is a free tool that can be used for this purpose.

- Reverse learning is based on the topic explanation by the teacher followed by the attempt of the student to convey their understanding of the material provided. It can be used to study a complex topic from different perspectives.

- Continuous learning combines various learning experiences ranging from classes under the guidance of a teacher to discussions with family members or online students.

- Learning to learn is a learning strategy that teaches students to learn, to manage their studies, develop skills, and assess learning outcomes. 
- Evaluation of information at a distance is a strategy that involves various explanations of past events, different sources of evidence or competing scientific models in order to support the development of strategies for understanding the world and provide opportunities for critical thinking.

- Making student thinking visible is a learning strategy that will be more effective if students can visualize their thinking. This may include setting goals, recording steps to address a problem, or annotation. Digital media, such as Twitter, YouTube, Facebook, blogs, wikis, Google Docs, WeChat and Padlet, encourage users to interact and collaborate, as well as provide feedback during the creation process, which allows students to ask additional questions. During real-time sessions, users can use the chat panel for video conferencing, document sharing, and text messaging, which helps students relate their assumptions to the ways of discussing ideas within the discipline.

- Leaning upon request involves the active study of the issue that interests the student; in this case, a smartphone can be used as a tool.

- Distance science includes learning in remote laboratories that allows students to study concepts and conduct research using high-quality data sets. Online experiments give students access to equipment and materials that would otherwise be too expensive, complex, or time-consuming.

- Massive open online courses (MOOC) are open online courses that have been designed for the general public and contain good quality examples of both oral and written speech.

- The Institute of Distance Learning Technologies is an approach that works well with practical and creative subjects and develops skills that can be applied in any field of learning as it is based on successful learning models that are used in the workplace and everyday life.

Models of online higher education programs are open, flexible and technological [20]; however, there are also a number of problems and concerns, which are, in particular, described in UNESCO documents [21]. These problems have become relevant today due to the forced and universal sudden transition to distance education associated with the COVID-19 pandemic.

The role of social networks in the development of online education. Prioritization is the basis for developing the pedagogy to counteract isolation and establishing deep connections between students and teachers through remote and indirect knowledge and meetings that compensate for the lack of pedagogical relations [21]. Social networks are widely used by undergraduate students as the sources of research despite the poor reliability they are usually characterized by [22]. Social networks have become the most prevalent form of communication and self-expression; thus, researchers note the inevitability of their impact and indicate that it is vital to be aware of social media [23] as they allow people to interact freely, which is of great theoretical and practical importance in all areas, including education. There is a sharp increase in the use of social networking sites by university students for various purposes. However, little is known about the use of social networks for educational purposes [24]. Social networks have been successfully used for teaching psychological, pedagogical 
or humanitarian sciences for a long time; however, the possibility of teaching medicine online is still a debatable issue. However, a study conducted at Saudi and Kuwaiti medical schools [24] found that the use of social networks on the Internet in medical education is a rapidly evolving field of research while the rare use of social networks for information exchange and significant differences in the perceptions of social networks by medical students should draw the attention of politicians to awareness raising and education reforms [24]. The development of advanced technologies and the advent of computers and the Internet have exponentially increased the use of Internet-based medical transformations, and a similar survey of medical students, staff physicians and doctors in the USA revealed that there is a growing use of social media by young medical students. As for the use of social networks for educational purposes, students turn to these platforms to make presentations, schedule events, develop teamwork, participate in group discussions, facilitate and evaluate learning, support teachers, and update regional and global knowledge. However, the study [24] failed to determine the impact of social networks on student performance. Innovative technologies in the digital world have changed the landscape of educational trends due to the use of smartphones and tablets for QR codes, virtual learning, and games [24]. Teachers are also encouraged to integrate YouTube into their courses to take advantage of its learning/teaching nature [25].

\section{Methods}

\subsection{Research design}

The research was carried out in several stages. At the first stage of the research, the topic of the study was determined, the analysis of scientific literature sources on the use of ICTs in higher education was carried out, and the relevance of the study was argued. At the second stage, the object, subject, purpose and objectives of the study were determined, and the hypothesis of the research was formulated. Next, in accordance with the objectives set, questionnaires were drawn up to study the readiness of students and teachers of Moscow City University to use ICTs. Based on the randomization principle, a group of respondents was formed and an anonymous survey was conducted; the survey results allowed us to determine the predictors of ICT use in higher education and to develop practical recommendations for higher educational institutions.

\subsection{Research sample}

The sample of undergraduate and graduate students and teachers of Moscow City University was randomized; it included the representatives of the Institute of Humanities (areas of study: sociology, history, foreign language; philology, including foreign philology; pedagogical science (History and foreign language; History and social studies, Russian language and literature)). The institute has about 1500 students and 230 teachers. In total, 218 students and 196 teachers were interviewed. 
Sample justification and study limitations. We have chosen to conduct a humanitarian institute, since for the specialties of this institute, the use of information and communication technologies has specific features. On the one hand, distance learning forms have long been used for mastering languages, on the other hand, teaching humanitarian specialties has traditionally been based on classroom studies. Thus, the active introduction of online forms of education, the use of information and communication technologies in the educational process of a humanitarian institute is an innovative step, and it was interesting for us to study the attitude of both students and teachers to this process. It was important to determine the psychological and competence-based readiness of the participants in the pedagogical process at the Humanitarian Institute for a new educational paradigm with an emphasis on the predominant use of information and communication technologies and online forms of education. At the same time, the choice of exclusively representatives of the Humanities Institute for research creates certain limitations, since the results obtained are relevant, first of all, for this contingent of respondents. That is, if a randomized sample of participants in our study can be extrapolated to all representatives of the humanitarian direction of education, then for technical specialties the answers about the use of information and communication technologies in the process of generalization with a high degree of probability may turn out to be completely different. Our study involves the study of the use of information and communication technologies in teaching humanitarian specialties, and comparison in this context with other specialties is a promising area of further research. That is, this study can be considered as a preliminary, pilot, and in the future, it is planned to expand it to other faculties of Moscow State University, as well as to compare with other universities in Russia and other countries.

The research methodology was based on a specially designed questionnaire, which included key questions aimed at assessing the use of ICTs and their impact on student performance. Statistical data processing was carried out on medstatistic.ru.

The assessment of the reliability and stability of the questionnaire results was checked by repeated testing by the "test-retest" method on the same sample at a fixed time interval (two weeks). Then the results were compared by comparing the mean values and determining the rank correlation coefficient - Spearman "; the statistical significance of the coefficient was determined on the basis of the Student's t-test.

The data analysis involved the following two steps: determining the level of ICT use in the educational process and comparing the indicators of the two groups of respondents - students and teachers.

\subsection{Ethical issues}

The survey was conducted anonymously, there were no people who refused to participate in the survey. The respondents were not differentiated by sex and age as this was not part of the research objectives. 


\section{$4 \quad$ Results and Discussion}

The students and teachers were asked to fill in a specially designed questionnaire that consisted of 40 closed-ended questions based on a five-point Likert scale [20]; the results of the survey are presented in Table 1.

Table 1. The assessment of the use of ICTs in the educational process by students and teachers

\begin{tabular}{|c|c|c|c|c|c|}
\hline \multirow{2}{*}{ No. } & \multirow{2}{*}{ Question } & \multirow{2}{*}{\begin{tabular}{|c|} 
Students \\
median \\
\end{tabular}} & \multirow{2}{*}{\begin{tabular}{|c|} 
Teachers \\
median \\
\end{tabular}} & \multirow{2}{*}{ t-test } & \multirow{2}{*}{$\mathbf{P}$} \\
\hline & & & & & \\
\hline 1 & $\begin{array}{l}\text { Do you take the advantage of social networks and cloud compu- } \\
\text { ting in the educational process? }\end{array}$ & 4 & 3 & 7.07 & $<0.05$ \\
\hline 2 & $\begin{array}{l}\text { Do you think that educational and scientific information found on } \\
\text { social networks is reliable? }\end{array}$ & 3 & 3 & 0.00 & $>0.05$ \\
\hline 3 & Do you use social networks for entertainment? & 5 & 2 & 21.21 & $<0.05$ \\
\hline 4 & $\begin{array}{l}\text { Do you use social networks for the educational information ex- } \\
\text { change? }\end{array}$ & 4 & 4 & 0.00 & $>0.05$ \\
\hline 5 & $\begin{array}{l}\text { Do social networks have a positive impact on student perfor- } \\
\text { mance? }\end{array}$ & 3 & 2 & 7.07 & $<0.05$ \\
\hline 6 & Do you prefer virtual textbooks to physical ones? & 3 & 2 & 7.07 & $<0.05$ \\
\hline 7 & Do you use any websites in the educational process? & 4 & 4 & 0.00 & $>0.05$ \\
\hline 8 & $\begin{array}{l}\text { Do you have any difficulties associated with the Internet access } \\
\text { and the use of ICTs? }\end{array}$ & 4 & 4 & 0.00 & $>0.05$ \\
\hline 9 & $\begin{array}{l}\text { Are new learning methods being introduced in your educational } \\
\text { institution? }\end{array}$ & 3 & 4 & 7.07 & $<0.05$ \\
\hline 10 & $\begin{array}{l}\text { Are simulations and VR technologies used in your educational } \\
\text { institution? }\end{array}$ & 2 & 2 & 0.00 & $>0.05$ \\
\hline 11 & $\begin{array}{l}\text { Are there any arguments that support the introduction of online } \\
\text { learning in your specialty? }\end{array}$ & 5 & 3 & 14.14 & $<0.05$ \\
\hline 12 & $\begin{array}{l}\text { Can online technologies make the pedagogical approaches to the } \\
\text { current curriculum more effective? }\end{array}$ & 4 & 3 & 7.07 & $<0.05$ \\
\hline 13 & Is distance learning implemented in your educational institution? & 5 & 5 & 0.00 & $>0.05$ \\
\hline 14 & $\begin{array}{l}\text { Is online learning integrated with the available courses (blended } \\
\text { learning)? }\end{array}$ & 5 & 5 & 0.00 & $>0.05$ \\
\hline 15 & $\begin{array}{l}\text { Do you have fully interactive online programs in your educational } \\
\text { institution? }\end{array}$ & 1 & 1 & 0.00 & $>0.05$ \\
\hline 16 & Is there a need to expand online learning? & 5 & 3 & 14.14 & $<0.05$ \\
\hline 17 & Are ICTs being implemented in general education? & 3 & 4 & 7.07 & $<0.05$ \\
\hline 18 & $\begin{array}{l}\text { Is the ICT development a leading strategic goal of your education- } \\
\text { al institution? }\end{array}$ & 2 & 3 & 7.07 & $<0.05$ \\
\hline 19 & Does ICT use affect academic performance? & 3 & 2 & 7.07 & $<0.05$ \\
\hline 20 & $\begin{array}{l}\text { Do you know that there are massive open online courses } \\
\text { (MOOC)? Do you use them in your educational pro- } \\
\text { cess/work/studies? }\end{array}$ & 2 & 4 & 14.14 & $<0.05$ \\
\hline 21 & $\begin{array}{l}\text { Do you have access to particular educational content and resources } \\
\text { any time? }\end{array}$ & 2 & 2 & 0.00 & $>0.05$ \\
\hline 22 & Are you satisfied with the design of the curricula? & 2 & 2 & 0.00 & $>0.05$ \\
\hline 23 & $\begin{array}{l}\text { Do students in the online environment receive the same } \\
\text { knowledge and student experience as in the traditional classroom? }\end{array}$ & 1 & 1 & 0.00 & $>0.05$ \\
\hline 24 & Are there any cultural barriers to the development of online learn- & 4 & 5 & 7.07 & $>0.05$ \\
\hline
\end{tabular}




\begin{tabular}{|c|c|c|c|c|c|}
\hline & ing technologies in your educational institution? & & & & \\
\hline 25 & $\begin{array}{l}\text { Does your institution provide sufficient support for institutional IT } \\
\text { and administrative systems? }\end{array}$ & 4 & 4 & 0.00 & $>0.05$ \\
\hline 26 & $\begin{array}{l}\text { Is your educational institution ready for the implementation of } \\
\text { continuous online learning? }\end{array}$ & 2 & 2 & 0.00 & $>0.05$ \\
\hline 27 & Is flipped learning implemented in your educational institution? & 1 & 2 & 7.07 & $<0.05$ \\
\hline 28 & Is reverse learning implemented in your educational institution? & 3 & 3 & 0.00 & $>0.05$ \\
\hline 29 & Are you aware of the concept of continuous learning? & 1 & 2 & 7.07 & $<0.05$ \\
\hline 30 & Are students taught to become effective distance learners? & 3 & 3 & 0.00 & $>0.05$ \\
\hline 31 & $\begin{array}{l}\text { Are thinking visualization techniques used in the educational } \\
\text { process? }\end{array}$ & 3 & 3 & 0.00 & $>0.05$ \\
\hline 32 & $\begin{array}{l}\text { Is training aimed at the development of critical thinking and the } \\
\text { ability to independently work with online information? }\end{array}$ & 2 & 3 & 7.07 & $<0.05$ \\
\hline 33 & $\begin{array}{l}\text { Do you use a smartphone in class to find the necessary educational } \\
\text { information? }\end{array}$ & 5 & 2 & 21.21 & $<0.05$ \\
\hline 34 & $\begin{array}{l}\text { Do you use remote laboratories and conduct experiments via the } \\
\text { Internet? }\end{array}$ & 1 & 1 & 0.00 & $<0.05$ \\
\hline 35 & Do you use YouTube as an additional learning tool? & 3 & 2 & 7.07 & $<0.05$ \\
\hline 36 & $\begin{array}{l}\text { Is the increased use of ICT in the educational process a positive } \\
\text { factor? }\end{array}$ & 4 & 3 & 7.07 & $<0.05$ \\
\hline 37 & Are teachers ready to use ICTs in the educational process? & 2 & 3 & 7.07 & $<0.05$ \\
\hline 38 & Are students ready to use ICTs in the educational process? & 4 & 2 & 14.14 & $<0.05$ \\
\hline 39 & Does ICT use improve academic performance? & 3 & 2 & 7.07 & $<0.05$ \\
\hline 40 & $\begin{array}{l}\text { Does the use of ICT has a positive impact on the formation of } \\
\text { professional competencies of students? }\end{array}$ & 4 & 3 & 7.07 & $<0.05$ \\
\hline & Correlation coefficient & \multicolumn{2}{|c|}{0.622} & 4.893 & \\
\hline
\end{tabular}

The questionnaire was compiled based on the key questions [18] that often arise when organizing online learning and can be useful for defining a strategy and developing tactical steps of ICT use in the educational process. The questionnaire also included questions that allow assessing the level of ICT use, the impact of ICT on academic performance and the formation of professional competencies of students, as well as identifying the limitations and problems of the implementation of online learning and the development of ICT in this particular educational institution. Most students' answers correlated with the teachers' responses, but there were also significant discrepancies on a number of questions.

Identifying the problems of using ICT in education. Both students and teachers confirmed the problems of Internet access and the quality of communication despite the fact that the educational institution implements distance programs and online learning is integrated into some courses. Although both groups of respondents indicated an active use of websites in the educational process, they noted the lack of fully interactive online courses and could not mention any simulation or virtual reality technologies used for teaching students.

Results of studying the use of social networks in the educational process. Despite the fact that compared to teachers students more often use the advantages of social media technologies in the educational process, both groups of respondents indicated that they did not trust educational and scientific information found on social networks. At the same time, students and teachers turn to social media to actively exchange 
information, share lecture notes, and discuss problematic issues. In contrast to teachers, students are more likely to use social networks for entertainment while teachers are more interested in the possibility of using social media as a source of information to optimize the educational process. Interestingly, most students and teachers still prefer printed books to online textbooks; however, students more often use online textbooks while teachers do not see their advantages over physical books.

The results of the study of the attitude of students and teachers to online learning and its prospects. It has been found that students are not aware of the introduction of new learning methods in their educational institution; however, they unanimously noted the advantages of online learning - the respondents believe that pedagogical approaches to the current curriculum can benefit from the use of ICT. Educators were more skeptical about the benefits of ICTs and could not provide enough arguments for online learning. It is noteworthy that according to students, the development of ICT is not a strategic goal of the educational institution; this opinion is also shared by many teachers. It should be highlighted that despite the fact that among the respondents there were both teachers of a foreign language and foreign philology, and students studying foreign languages at the Institute of Humanities, they also turned out to be insufficiently aware of the possibilities of online learning provided by massive open online courses (MOOC) [14], which mainly offer the development of foreign language competencies. At the same time, many teachers believe that there is great attention paid to this area while students do not have enough information about the issue. Both students and teachers noted the lack of anytime access to educational content and activities, and expressed dissatisfaction with the design of the curriculum being used; however, they failed to clearly describe what they did not like and what changes should be made. Students and teachers agreed that online learning does not ensure the same level of knowledge and student experience that can be obtained in the traditional classroom environment highlighting the lack of readiness of the institution for continuous online learning; however, they also indicated that there is enough support for the institutional ICT and administrative systems. It is probably the presence of cultural barriers, stereotypes and fears, noted by almost all respondents, that is the major obstacle to the more extensive use of ICTs in the educational process. Another common problem is the awareness of and familiarity with modern foreign methods of online education and the use of ICT. It was revealed that not only students but also teachers are not familiar with practical approaches to distance learning - the concepts of flipped, reverse and continuous learning were new for them [9]; however, a number of respondents noted that students are supported to become effective distance learners. It would be interesting to clarify the support in more detail, obtain its description by students and teachers, as well as define its efficiency in the educational process. However, both students and teachers indicated the use of thinking visualization techniques in the educational process, which mainly occurs in the form of making presentations. Teachers are more optimistic about the formation of students' critical thinking and the ability to independently work with online information while students consider these competencies to be underdeveloped and need support from teachers when working with online sources. Interestingly, almost all students noted the use of a smartphone in the classroom as a source of necessary educational information while teachers were 
strongly opposed to this. However, today a smartphone is the tool that contributes to continuous learning and (or) learning upon personal request; therefore, it is an important educational resource provided that it is used strictly for its purpose [14]. Thus, a lot of teachers are at the mercy of "institutional myths" and very vague ideas about online learning [19]; psychologically, they are not ready for changes and do not want to leave the "comfort zone" [19]. This also applies to the use of the YouTube platform as an extra tool for learning. Despite the fact that it is used by many students, the majority of teachers do not consider the platform as an educational resource mistakenly believing that only entertainment videos can be found there. At the same time, on YouTube, there is free video content covering a number of academic disciplines, including videos created by students as tests; the materials are visual and informative, as well as corresponding to curricula and programs. Therefore, it is not surprising that the majority of students noted that teachers were not ready to use ICT in the educational process while the teachers rated their attitude to this problem much higher. As for the readiness of students to use ICTs in the educational process, the situation turned out to be the exact opposite: the students expressed sufficient readiness while the teachers rated their chances much lower. In addition, students noted the positive impact of the use of ICTs both on academic performance and, in particular, on the development of professional competencies in contrast to the teachers who had another opinion. The teachers confirmed the correlation between the use of ICTs and the formation of competencies but did not confirm the impact of ICT on academic performance. These discrepancies indicate the presence of some communication barriers of misunderstanding between students and teachers, which negatively affects the introduction of progressive innovations into the educational process and requires further research in order to develop new approaches to improving the interaction and cooperation between the educational process participants.

Generalization of research results. Thus, the research results confirm the data of scientific literature [19] that it is the lack of readiness of teachers for innovative changes in the educational process that is the major obstacle to the technological progress in higher educational institutions while the expansion of online learning provides a strategic view of its various models and the consequences of its implementation at the institutional level [19]. Online learning should be as high-quality and reliable as traditional courses [19], which naturally increases the requirements for the competencies of teachers and their methodological load; in case of cognitive inertia, this causes some psychological resistance, a feeling of vulnerability and unwillingness to change [19], which is confirmed by the results of our study. It is necessary not only to improve the provision of ICTs in an educational institution but also to ensure targeted professional development of teachers who must learn to work in the new environment and perform new functions, contribute to the formation of students' skills of independent work and self-management, and provide support for students in distance learning. Teachers should master flipped learning skills, which combine teacherdirected instruction with independent student learning. As for reverse learning, it was used in traditional classrooms earlier but there was no official name and the strategy was more focused on the assessment of the student answer rather than the quality digestion of the educational material. In order to ensure continuous learning, teachers 
must provide students with the opportunity to use whatever resources they need, including not only books, notebooks, and pens, but also smartphones and computers, as well as the involvement of family members as sources of information - this is the only way to give students more responsibility and motivate them to search for the resources that can help them master the educational content [9].

In order to teach a student to be an effective distance learner, the teacher should master appropriate skills and techniques. The learning to learn strategy involves the ability to set goals, plan their achievement, find the necessary resources, communicate effectively, choose learning strategies, reflect on progress, develop creative skills and evaluate learning outcomes [9]. Thus, the teacher must provide students with the structure, resources and motivation they need to learn. Despite the fact that distance learning implies a great responsibility of the student, they can become independent learners only when there is teacher support in finding sources of knowledge, using the appropriate online networks, developing communication and teamwork skills, flexibility and creativity in new situations [9].

Evaluation of information at a distance involves the use of not only a textbook but also various alternative sources of information, which requires the teacher to have broad-based knowledge and criteria for evaluating events, scientific facts, and models. When students are taught to evaluate information, they understand that knowledge is a complex and diverse phenomenon - it evolves over time and is based on a variety of sources of information - as well as master strategies that can be used to distinguish strong evidence from good arguments [9].

Teachers rather often use visualization of thinking, but it comes down mainly to the creation of presentations and is usually very formal. At the same time, there are various ways to visualize thinking in distance learning [9], for example, by asking targeted questions and setting deadlines for responses, planning lessons based on responses, and using digital media such as Twitter, YouTube, Facebook, blogs, wikis, etc. [9]. However, most teachers being at the mercy of stereotypical prejudices against social networks and not always having a proper command of ICT are ready to do this. Both students and teachers should realize that a smartphone in class is not a toy but a tool for finding answers to educational questions. In this aspect, students need the support of teachers who will help them understand what types of questions are scientifically acceptable and how the data collected can be analyzed and presented as reliable evidence [9]. The rapid development of technology raises risks and concerns; however, it also provides new opportunities for gaining knowledge and managing information, which must be taken into account when creating an effective online learning environment in an educational institution [11].

Unfortunately, a number of domestic students and teachers are still not aware of MOOCs and the possibilities of distance learning and scientific research in remote laboratories. They often doubt the possibility while currently there are remote laboratories allowing students to conduct remote research in a number of topic areas [9] and providing them with numerous advantages. The students who took part in our study may not be sufficiently aware of MOOCs and virtual laboratories as they are junior students and do not yet have enough skills for independent study. However, this resource is also improperly used by some teachers, which indicates their underestima- 
tion of the importance of using additional opportunities of ICT in education, inadequate attention to this issue and weak motivation to master innovative teaching methods. It should be noted that in the current global and rapidly changing environment, it is impossible to achieve professional success without mastering ICTs; therefore, in the context of the competitive education market, the priority will be given to those higher educational institutions that reshape the forms and methods of learning in accordance with the actual needs of ICT use.

\section{Conclusion}

The use of ICTs in higher education opens up new opportunities and simultaneously raises complex problems. Today online learning involves not only distance courses provided by traditional educational institutions, but also the development and growing popularity of open barrier-free and free online education. At the same time, online learning resources are increasingly used even in those areas where it used to be considered impossible and unacceptable, namely in medicine and scientific research with the help of virtual laboratories. Nevertheless, the issue of the quality of online education, which should not be inferior to traditional learning opportunities, has not been solved. However, both scientific literature and the results of our research indicate that both students and teachers still prefer offline classes and live communication to the use of ICTs. In addition, in most countries, online university degrees are not recognized at the state level or by employers despite the fact that in some countries they are equivalent to regular degrees.

A significant problem of the use of ICTs in higher education is the growing inequality associated with the problems of the Internet connection and access to social networks (which was also noted by the respondents in our study), especially in rural areas, and the difficulty of creating equal opportunities for online learners with disabilities, in particular, with limited possibilities of perception.

A serious obstacle to the use of ICT in higher education, which has been confirmed in our research, is cultural barriers, psychological rejection of innovation and adherence to traditional forms of education. Our research has shown that both teachers and students do not think that the educational and scientific information found on social networks is quite reliable; at the same time, they actively use social networks to exchange educational information, share lecture notes, and discuss problematic issues. Students and teachers still prefer printed books to online textbooks; however, students more often use online textbooks while teachers do not see their advantages over physical books.

We have identified a lack of awareness among students on the introduction of new learning methods in the educational institution; both students and teachers do not consider the use of ICT as a strategic goal of the educational institution. Students and teachers agreed that online learning does not ensure the same level of knowledge and student experience that can be obtained in the traditional classroom environment highlighting the lack of readiness of the institution for continuous online learning; however, they also indicated that there is enough support for the institutional ICT and ad- 
ministrative systems. Another common problem is the awareness of and familiarity with modern foreign methods of online education and the use of ICT. It turned out that not only students but also teachers are not familiar with modern practical approaches to distance learning and the capabilities of MOOCs and virtual laboratories.

The primary objective of ICT use in higher education is to improve the qualifications of teachers who are ready to take on new roles in relations with students, to help and support them in order to develop their skills of self-education, self-management, critical thinking needed for effective online learning.

The use of ICT improves the quality of education and competitiveness of higher educational institutions, contributes to the development of professional competencies, but does not have a significant impact on the academic performance of students.

It can be concluded that the predictors, that is, predictive parameters, of the use of ICT in higher education are blended learning focused on the use of online technologies and independent work of students, virtual laboratories, as well as the development of open education and the MOOC system. This conclusion is based on the results of our research, which made it possible to identify promising directions for the development of information and communication technologies in the educational process by comparing the points of view on this issue of students and teachers. The improvement of ICTs will be aimed at eliminating user inequality, ensuring free Internet connection and access to social networks, providing opportunities for people with disabilities to receive online education. Changes in the relationship between the teacher and students as equal educational process participants stimulate the professional development of teachers both in the field of mastering ICTs and in educational psychology. The development of standardized quality control criteria will ensure the equality of diplomas in online and offline education.

Thus, practical recommendations include placing the focus on the development of ICT as a strategic goal of an educational institution, improving the qualifications of teachers to work in the context of distance learning and teaching students the skills of independent work, using MOOCs and the capabilities of virtual laboratories in the educational process.

In the future, it is planned to expand the range of our research to other specialties. In addition, future research should be aimed at studying the psychological readiness of students and teachers for distance work, as well as developing and implementing quality assessment criteria for online education.

\section{References}

[1] Stracke, C.M. (2019). Quality Frameworks and Learning Design for Open Education. The International Review of Research in Open and Distributed Learning, 20(2): 180-203. https://doi.org/10.19173/irrodl.v20i2.4213

[2] Alfadil, M., Anderson, D., Green, A. (2019). Connecting to the digital age: using emergent technology to enhance student learning. Education and Information Technologies, 25: 1625-1638. https://doi.org/10.1007/s10639-019-10035-Z 
[3] Shraim, K. (2020). Quality Standards in Online Education: The ISO/IEC 40180 Framework. International Journal of Emerging Technologies in Learning, 15(19): 22-36. https:// doi.org/10.3991/ijet.v15i19.15065

[4] Obonya, J., Kadlečík, M. (2020). Assessing the Intensity of the Usability of the Course Content within the Virtual Learning Environment. International Journal of Emerging Technologies in Learning, 15(17): 165-180. https://doi.org/10.3991/ijet.v15i17.13715

[5] Enakrire, R.T. (2019). ICT-related training and support Programmes for information professionals. Education and Information Technologies, 24(6): 3269-3287. https://doi.org/10. $\underline{1007 / \mathrm{s} 10639-019-09931-1}$

[6] Vlachopoulos, D. (2016). Assuring quality in online course design: The roadmap. The International Review of Research in Open and Distance Learning, 17(6): 183-205. https://doi.org/10.19173/irrodl.v17i6.2784

[7] Ransom, T., Knepler, E., Zapata-Gietl, C. (2018). New Approaches to Judging Quality in Higher Education: Profiles of Emerging Methods Apart from Traditional Accreditation. CHEA/CIQG Publication Series. Council for Higher Education Accreditation. https://ww w.chea.org/new-approaches-judging-quality-higher-education https://doi.org/10.1080/037 9772022000071913

[8] Cömert, N., Akgun, I., Karaköy, D., Kaya, P. (2019). Quality Management Approaches and Their Comparison inHigher Education: Marmara University Faculty of Business Administration Quality Studies. The Online Journal of Quality in Higher Education, 6(3): 101-111.

[9] OU-UK (2018). Online Learning in Tertiary Education in the Middle East and North Africa. Open University, UK. http://www.open.ac.uk/research/sites/www.open.ac.uk.research/ files/files/Documents/Online\%20learning\%20in\%20tertiary\%20education\%20in\%20the\% 20Middle\%20East\%20and\%20North\%20Africa\%20.pdf.https://doi.org/10.9737/hist.2018. 644 https://doi.org/10.9737/hist.2018.644

[10] Koliadenko, N. V. (2013), Ensuring the right of people with disabilities to professional self-realization. Management of a health care institution, 1: 74-83

[11] Verhoeven, J.C., Heerwegh, D., De Wit, K. (2016). ICT learning experience and research orientation as predictors of ICT skills and the ICT use of university students. Education and Information Technologies, 21(1): 71-103. https://doi.org/10.1007/s10639-014-9310-3

[12] Kukulska-Hulme, A. (2016). Personalization of language learning through mobile technologies. Cambridge University Press, Cambridge, UK.

[13] Jaimez-González, C., Martínez-Samora, J. (2020). DiagrammER: A Web Application to Support the Teaching-Learning Process of Database Courses through the Creation of ER Diagrams. International Journal of Emerging Technologies in Learning, 15(19): 4-21. https://doi.org/10.3991/ijet.v15i19.14745

[14] Open University (2017). Innovating Pedagogy report series. http://www.open.ac.uk/blogs/i nnovating/

[15] Online Course Report (2017). State of the MOOC 2017: A Year of Privatized and Open Education Growth. https://www.onlinecoursereport.com/state-of-the-mooc-report/

[16] Ferrell, G., Smith, R., Knight, S. (2018). Designing learning and assessment in a digital age. Section on Learning Analytics. https://www.jisc.ac.uk/guides/designing-learning-andassessment-in-a-digital-age/learning-analytics https://doi.org/10.18608/jla.2018.53.1

[17] Ferrell, G., Smith, R., Knight, S. (2018). Designing learning and assessment in a digital age. Section on Quality. https://www.jisc.ac.uk/guides/designing-learning-and-assessmentin-a-digital-age/quality

[18] Jisc (2016). Curriculum design and support for online learning. https://www.jisc.ac.uk/fullguide/curriculum-design-and-support-for-online-learning 
[19] Jisc (2016). Scaling up online learning. https://www.jisc.ac.uk/full-guide/scaling-up-online -learning

[20] Orr, D., Weller, M., Farrow, R. (2018). Models for online, open, flexible and technology enhanced higher education across the globe - a comparative analysis. Final Report. International Council for Open and Distance Education, Norway.

[21] UNESCO UIS (2013). A Teacher for Every Child: Projecting Global Teacher Needs from 2015 to 2030. UNESCO fact sheet 27. UNESCO, Paris.

[22] Aslan, S.A., Duruhan, K. (2020). The effect of virtual learning environments designed according to problem-based learning approach to students' success, problem-solving skills, and motivations. Education and Information Technologies, 1: 1-31. https://doi.org/10.1007 /s10639-020-10354-6

[23] Appel, G., Grewal, L., Hadi, R., Stephen, A. T. (2020). The future of social media in marketing. Journal of the Academy of Marketing Science, 48(1): 79-95. https://doi.org/10.100 7/s11747-019-00695-1

[24] Guraya, S.Y., Almaramhy, H., Al-Qahtani, M.F., Guraya, S.S., Bouhaimed, M., Bilal, B. (2018). Measuring the extent and nature of use of social networking sites in medical education (SNSME) by university students: Results of a multi-center study. Medical Education Online, 23(1): 1505400. https://doi.org/10.1080/10872981.2018.1505400

[25] Moghavvemi, S., Sulaiman, A., Jaafar, N.I., Kasem, N. (2018). Social media as a complementary learning tool for teaching and learning: The case of youtube. International Journal of Management Education, 16(1): 37-42. https://doi.org/10.1016/j.ijme.2017.12.001

\section{$7 \quad$ Authors}

Tokareva Elena Anatolievna is a PhD of History, Professor of the Department of National History, Moscow City University, Moscow, Russian Federation. tokarevelena@yandex.ru

Malysheva Olga Geraldovna is a Doctor of History, Professor of the Department of National History, Moscow City University, Moscow, Russian Federation.

Smirnova Yulia Valerievna is a $\mathrm{PhD}$ of History, Associate Professor of the Department of National History, Moscow City University, Moscow, Russian Federation.

Orchakova Larisa Gennadevna is a Doctor of History, Professor of the Department of National History, Moscow City University, Moscow, Russian Federation.

Article submitted 2020-11-25. Resubmitted 2021-04-21. Final acceptance 2021-04-24. Final version published as submitted by the authors. 